\title{
In Memoriam: Catherine Morrison Paul, 1953-2010
}

\author{
Lilyan Fulginiti
}

Published online: 6 December 2013

(c) Springer Science+Business Media New York 2013

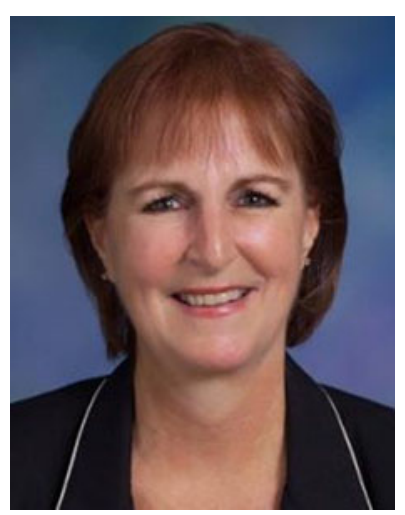

Catherine Morrison Paul left an impressive legacy of economic analysis prior to her untimely death in 2010. She started her odyssey into the economics of productivity analysis as a graduate student at the University of British Columbia, where she received her Ph.D., at the Center for Japan-US Business and Economic Studies of New York University, and through academic appointments at Tufts University and the University of California-Davis. She stands out as one of the very best empirical production economists in her 30 years in the profession. She carved out a very clear area of work around measurement of economic performance at the firm, sector and economy level. She used production theory tools to model, construct, interpret, and implement economic performance measures. To do this she focused on the cost structure of the firm and on how it reflected productivity growth. She also made fundamental methodological and empirical contributions to

L. Fulginiti ( $\square)$

University of Nebraska-Lincoln, 307C Filley Hall, Lincoln, NE 68583, USA

e-mail: 1fulginiti@unl.edu

our knowledge of industry structure and to the role that economies of size and capacity utilization play in determining performance. Two recurrent themes summarize Catherine Morrison Paul's research contributions: the use of production theory to study economic performance and careful analysis of empirical data.

Her contributions, both direct (scientific contributions) and indirect (students, colleagues, other economists) can be grouped in two areas: research linking economic performance to cost and production characteristics and an emphasis on empirics. She aptly used these tools to analyze issues as diverse as productivity in the US automobile industry, terms of trade impacts on the Japanese manufacturing industry, capital investments in the US food processing industry, market power in the meatpacking industry, efficiency of airports and hospitals, and capacity utilization in the fishing industry.

She estimated cost functions, production functions, distance functions, and transformation functions, alone and in systems of equations, using instrumental variables when appropriate, incorporating time series and spatial econometrics, using latent variables and Bayesian methods on occasion. The diverse areas of application and her rate of output reflect an impressive ability to work with large data sets, and an enormous devotion to her craft, even the tedious work involved in the manipulation needed to prepare data for model estimation.

She showed an ability to work in many areas and with many different collaborators, as evidenced by her publications, ${ }^{1}$ her advisory roles on expert panels and interaction

\footnotetext{
${ }^{1}$ She published approximately 70 articles in peer reviewed journals with 31 different collaborators, a book, and numerous monographs and reports. She was ranked top $5 \%$ in RePEc, July 2011 and was elected Fellow of the American Agricultural Economics Association in 2006.
} 
with agencies such as the USDA, the Federal Reserve Board, the General Accounting Office, the National Marine Fisheries Service, US Bureau of Labor, and FEMA.

She had command of the discipline of economics as well as of the scientific method. She used both to uncover facts of the real world and complemented them with traits of character such as inquisitiveness, creativity, and tenacity. Taken together these made her one of the most outstanding applied production economists of her generation.

The three papers in this special section of the journal were invited to be presented at a session in celebration of Catherine Morrison Paul's work that took place at the 7th North American Productivity Workshop at Rice University, June 6-9, 2012. Three of Cathy's friends, well known production economists, were invited to develop papers. They were asked to write new material that would have awakened Cathy's curiosity and interest. Grifell-Tatje and Lovell chose to focus on the concept of capacity utilization, reminding us that Cathy devoted a large part of her career to the micro-foundations of this performance measure. Diewert thought to expand on concepts introduced in Morrison and Diewert (1986), their first published collaboration, in which they sought to distinguish terms of trade effects from productivity effects in growth and welfare analysis. Chambers, Karagiannis and Tzouvelekas examine the impact of pest-damage prevention technologies on agricultural productivity growth, taking us to the last years of Cathy's career among agricultural economists. 